DOI: 10.12731/2070-7568-2018-2-57-76

УДК 65.011.46

\title{
МЕТОДИКА ОЦЕНКИ ВОЕННО-ЭКОНОМИЧЕСКОГО ЭФФЕКТА, ПОЛУЧАЕМОГО ПРИ ВНЕДРЕНИИ ТЕХНОЛОГИЙ «ИНДУСТРИИ 4.0» В СФЕРЕ ВЕЩЕВОГО ОБЕСПЕЧЕНИЯ ВОЕННЫХ ПОТРЕБИТЕЛЕЙ
}

\section{Красовитов P.A.}

В современных условиях происходит быстрое развитие инструментов повыпения эффективности логистических систем, основанных на сочетании гибкого сотрудничества между элементами, входящими в их состав, иирокого использования средств автоматизачии и информатизации и адаптации конечного продукта к специфическим запросам конкретного заказчика (т. н. технологий «Индустрии 4.0»). Сложность оченки военно-экономического эффекта от применения инструментария «Индустрии 4.0» в сфере вещевого обеспечения войск (сил) связана с тем, что факторы (составляющие) этого эффекта, во-первых, имеют разную природу (что усложняет их непосредственное сопоставление), во-вторых, зачастую трудно измеримы, из-за чего оченка совокупного военно-экономического эффекта неизбежно будет носить приблизительный характер.

Цель работы: построение методики оченки военно-экономического эффекта от применения «Индустрии 4.0» в сфере вещевого обеспечения военных потребителей.

Методы: общенаучные методы анализа и синтез, метод экономико-математического моделирования.

Результаты: на основе выявления факторов, обуславливающих возникновение военно-экономического эффекта, построена методика оценки военно-экономического эффекта от применения инструментов «Индустрии 4.0» в сфере вещзевого обеспечения войск (сил).

Ключевые слова: военные потребители; вещевое обеспечение войск; военно-экономический эффект; «Индустрия 4.0». 


\section{A METHOD OF EVALUATION OF MILITARY AND ECONOMIC EFFECT PRODUCED BY TECHNOLOGIES OF THE "INDUSTRY 4.0" IN THE FIELD OF MATERIAL SUPPLY TO MILITARY CUSTOMERS}

\section{Krasovitov R.A.}

Modern situation is characterized by fast development of tools that increase effectiveness of logistical systems. These tools are based on combination offlexible cooperation between their elements, broad us of automation and informatization and adaptation of the final product to the specific needs of the customers (technologies of the "Industry 4.0"). It is very difficult to evaluate the military and economic effect produced by the "Industry 4.0" in the field of material supply to the armed forces because factors of this effect have different nature and cannot be compared directly and because these factors are often not measurable (tis is why the evaluation of this effect will be only approximate).

Goal of the paper: working out a method of evaluation of military and economic effect produced by using "Industry 4.0" in the field of material supply to military customers.

Methods: analysis, synthesis, economic and mathematical modelling.

Results: factors of military and economic effect were identified and a method of evaluation of military and economic effect produced by use of tools of the "Industry 4.0" in the filed of material supply to armed forces was proposed.

Keywords: military customers; material supply to armed forces; military and economic effect; "Industry 4.0".

\section{Введение}

Несмотря на то, что в настоящее время развитие цифровой экономики (и, в частности, «Индустрии 4.0») считается основным трендом эволюции хозяйственной жизни [21, 23-25], применение цифровых инструментов на практике тормозится по причине того, что неясно, каким образом можно оценить интегральный эффект от их 
внедрения. Это в определенной степени мешает принимать решения о целесообразности использования соответствующих технологий. Для России данная проблема имеет особое значение, поскольку ускоренное внедрение технологий «Индустрии 4.0» может позволить нашей стране перескочить через один этап технологического развития и тем самым устранить отставание от передовых государств. По этой причине исключительно важно разработать методику обоснования целесообразности применения технологий «Индустрии 4.0», ключевым элементом которой будет являться оценка интегрального эффекта от использования этих технологий.

Особенно важно предложить такую методику для обоснования применения цифровых технологий в военной сфере. Сейчас, в условиях жесткого геополитического давления, нашей стране необходимо сохранять паритет с ведущими военными державами мира (прежде всего - с США и возглавляемым ими военным блоком НАТО), которые в совокупности имеют подавляющее превосходство по численности личного состава, количеству вооружений и военной техники и потенциалу оборонной промышленности. Инструментом обеспечения такого паритета (который может быть достигнут только за счет создания у Вооруженных Сил Российской Федерации (ВС РФ) потенциала эффективных асимметричных действий) может быть внедрение технологий «Индустрии 4.0» в военной организации государства. Однако для того, чтобы это внедрение действительно способствовало росту оборонительной мощи нашей страны, а не превратилось в бесполезное расходование бюджетных средств, необходима методика оценки ожидаемого интегрального (военно-экономического) эффекта от применения соответствующих технологий в военной сфере.

В предлагаемой работе мы попытаемся предложить такую методику применительно к сфере вещевого обеспечения войск (сил).

В существующей литературе по управлению инновациями предложено довольно много методик для оценки интегрального эффекта от внедрения той или иной инновации $[2,3,5,6,9,10,12,14-16$, $22,26]$. Однако, как уже было сказано, для «Индустрии 4.0» таких методик пока предложено не было. Единственным исключением 
(причем, что очень важно, исследующим проблематику оценки эффекта от применения «Индустрии 4.0» с военно-экономической точки зрения), является статья [4]. Однако в ней затронут достаточно частный вопрос оценки эффекта от применения радиометок при организации вещевого снабжения военнослужащих войск Национальной гвардии Российской Федерации. Результаты, полученные в этой работе, не могут быть перенесены на другие области применения «Индустрии 4.0» в сфере организации вещевого обеспечения войск (сил).

С учетом специфики цифровых технологий использование для оценки ожидаемого от них интегрального эффекта на основе методик, разработанных для других типов инноваций, невозможно. При этом существующие методики могут быть использованы в качестве основы для построения методики оценки военно-экономического эффекта от применения технологий «Индустрии 4.0».

Очевидно, что в силу закрытости информации, в доступных источниках сведения о подходах к оценке военно-экономической эффекта от применения технологий «Индустрии 4.0» в военной сфере отсутствуют.

Это означает, что строить соответствующую методику нам придется самостоятельно.

\section{Методы}

В статье использованы общенаучные методы анализа и синтеза, а также метод экономико-математического моделирования.

\section{Результаты}

С учетом сущности показателя военно-экономического эффекта нам необходимо будет разработать методики оценки его отдельных элементов (экономического и военного эффектов), а также предложить методику оценки совокупного военно-экономического эффекта путем свертки частных показателей военного и экономического эффектов. В свою очередь, для оценки военного и экономического эффектов необходимо понимать, какие факторы приводят к форми- 
рованию этих эффектов, оказывают влияние на его повышение или снижение $[10,12]$. Эти факторы представлены в табл. 1.

Следует отметить, что, как было показано нами ранее в работе [13], в качестве отдельного фактора, ведущего к уменьшению экономического эффекта, в соответствии с рекомендациями, представленными в работе [11], следует принять риски потерь, т. е. те возможные убытки, которые могут возникнуть в случае неспособности системы вещевого обеспечения, построенной на основе технологий «Индустрии 4.0», выполнять свои функции в течение определенного периода. Эти риски в первую очередь обуславливаются недостаточной защищенностью системы от злоумышленников. По этой причине необходимо искать компромисс между инвестициями в обеспечение ее защиты и величиной возможных потерь. Однако не всегда потери можно компенсировать в денежном выражении. Ведомственная логистическая система существенным образом отличается от гражданской и на первое место в ней, как правило, выходят показатели надежности и оперативности [13].

Таблича 1.

Факторы, обуславливающие формирование экономического эффекта от применения технологий «Индустрии 4.0» в сфере вещевого обеспечения войск (сил) (составлено на основе [13] и собственных разработок автора)

\begin{tabular}{|c|c|}
\hline $\begin{array}{c}\text { Факторы, повышающие экономи- } \\
\text { ческий эффект от применения тех- } \\
\text { нологий «Индустрии 4.0» в сфере } \\
\text { вещевого обеспечения }\end{array}$ & $\begin{array}{c}\text { Факторы, снижающие экономический эффект от } \\
\text { применения технологий «Индустрии 4.0» в сфере } \\
\text { вещевого обеспечения }\end{array}$ \\
\hline Сокращение затрат на оплату тру- & Инвестиции в активы (оборудование, про- \\
\hline да персонала; & граммное обеспечение и т. д.), необходимые для \\
\hline снижение издержек на содер» & применения технологий «Индустрии 4.0»; \\
\hline избыточных активов; & затраты на ликвидацию избыточных активов; \\
\hline получение дохода от продажи & расходы на реинжиниринг бизнес-процессов; \\
\hline или передачи в аренду избыточных & переобучение и преодоление сопротивления \\
\hline активов; & персонала и военных потребителей; \\
\hline сокращение логист & расходы на ликвидацию (утилизацию) избы- \\
\hline жек, связанных с хранением и грузо- & точных активов; \\
\hline переработкой материальных средств; & инвестиции в обеспечение кибербезопасности; \\
\hline сокращение трансак & расходы на обеспечение функционирования \\
\hline держек; & технологий «Индустрии 4.0»; \\
\hline снижение стоимости & государственная поддержка поставщиков (воз- \\
\hline мых предметов вещевого обесп & можна на начальном этапе реализации проекта) \\
\hline
\end{tabular}


Отказ от избыточных активов связан с тем, что, благодаря гибкому производству и возможностью выполнения заказов точно в срок часть складов, предназначенных для хранения вещевого имущества, может быть ликвидирована (сокращена, переоборудована под хранение других видов материальных средств или законсервирована), что избавляет военную организацию государства от расходов на их дальнейшую эксплуатацию (и тем самым генерирует доход в виде экономии) [13]. Однако отказ от этих избыточных активов сам по себе может быть как источников доходов (если эти активы могут быть проданы сторонним организациям или переданы им в аренду), так и расходов (если военная организация вынуждена взять на себя затраты на их ликвидацию или консервацию) [13].

Снижение трансакционных (управленческих) издержек обуславливается оптимизацией бизнес-процессов, устранением промежуточных управленческих звеньев, минимизацией потерь и большим соответствием объектов вещевого обеспечения потребностям военнослужащих [7]. В частности, если в настоящее время при поставках, например, обуви доли обуви разных размеров фиксированы (заданы на основе специальных нормативов), что может стать причиной несоответствия получаемых размеров реальным антропометрическим характеристикам военнослужащих, то при использовании технологий «Индустрии 4.0» обувь изготавливается фактически индивидуально, что минимизирует расходы на её замену, возврат и т. д. [13].

Сопротивление личного состава [17] может возникать на разных уровнях. Это, прежде всего, сами сотрудники вещевой службы, которым придется перестраиваться с привычного им алгоритма выполнения своих обязанностей на принципиально новый, в рамках которого значительная часть ранее наработанных ими компетенций окажется невостребованной (что негативно скажется на их самооценке и может привести к саботажу нововведений). Сопротивляться может и личный состав, которому придется осваивать новые алгоритмы заказа и получения вещевого имущества. Однако на этом уровне сопротивление будет, вероятнее всего, довольно низким и может быть устранено путем проведения переобучения. 
Довольно высокими могут стать затраты на обеспечение кибербезопасности. Однако это неизбежное следствие внедрения цифровых технологий.

При этом, разумеется, степень реализации преимуществ, представленных в табл. 1, будет сильно различаться в зависимости от глубины внедрения «Индустрии 4.0». Если она будет внедрена только в вещевой службе, то это будет представлять собой только нарастание степени автоматизации и информатизации внутренних процессов этой службы, но не позволит обеспечить индивидуализацию объектов вещевого обеспечения [13] и не повысит качество системы вещевого обеспечения ВС РФ с внешними поставщиками. Напротив, если поставщики вещевого имущества для государственных нужд также внедрят в своей деятельности технологии «Индустрии 4.0», это позволит получить ожидаемый экономический эффект в полном объеме [13] (но при этом на первоначальном этапе придется либо оказать бюджетную поддержку поставщикам с целью полного или частичного софинансирования их перехода на технологии «Индустрии 4.0», либо согласиться с некоторым удорожанием поставляемых предметов вещевого обеспечения - так как при помощи этого поставщики могут попытаться компенсировать свои инвестиционные затраты). Иными словами, многое зависит от эффективности организации военно-гражданского сотрудничества $[8,18,19]$.

Это означает, что внедрение технологий «Индустрии 4.0» в сфере вещевого обеспечения ВС РФ может осуществляться разными способами, различающимися по глубине охвата, в силу чего как состав факторов экономического эффекта, так и итоговая величина этого эффекта могут значительно различаться. Сам же экономический эффект имеет комплексную природу, и ни в коем случае не следует подходить к его определению чрезмерно прямолинейно - необходимо принять тот факт, что получение высокого экономического эффекта в среднесрочной и долгосрочной перспективе может потребовать прироста затрат в краткосрочной перспективе. К сожалению, в настоящее время подход к организации закупок для государственных нужд в нашей стране очень часто делает невозможным принятие таких стратегических решений. 
Источниками военного эффекта служат [13]:

1) повышение качества выполнения военнослужащими своих обязанностей (из-за большего удобства предметов вещевого обеспечения благодаря их индивидуализации);

2) улучшение морального состояния военнослужащих (благодаря росту удовлетворенности условиями несениями службы). Отметим, что этот фактор благоприятно сказывается не только на боевом духе военнослужащих, но и на имидже Вооруженных Сил в целом. Это повышает их привлекательность для потенциальных кандидатов для несения службы, а также дает возможность несколько ограничивать рост служебных окладов (прирост качества вещевого обеспечения служит своего рода моральным стимулом, который может отчасти компенсировать денежную составляющую);

3) уменьшение времени на выполнение процессов вещевого обеспечения (за счет автоматизации, безбумажного оборота и устранения необходимости затрат труда управленческого персонала на обработку и согласование необходимых документов).

Большой проблемой является измерение этого военного эффекта. Для этого, в частности, могут быть использованы опросы военнослужащих.

Внедрение технологий «Индустрии 4.0» в сфере вещевого обеспечения военных потребителей связано со значительными инвестициями в разработку и введение в практическую эксплуатацию инновационных информационных технологий и физических активов. Таким образом, оценка экономического эффекта от применения «Индустрии 4.0» будет представлять собой оценку экономической эффективности соответствующего инвестиционного проекта.

В настоящее время существует множество показателей для проведения такой оценки (чистый дисконтированный доход, индекс доходности, срок окупаемости, внутренняя норма доходности и т. д.) [20]. У каждого из этих показателей есть своя сфера применения, однако большинству из них присущи значительные недостатки (связанные с методологией расчета и применения). От 
этих недостатков в целом свободны такие показатели, как чистый дисконтированный доход (дающий информацию о финансовой эффективности в абсолютном - денежном - выражении) и индекс доходности (в котором информация о финансовой эффективности содержится в относительном выражении). Мы полагаем, что более предпочтительным показателем с учетом наших целей является чистый дисконтированный доход ЧДД. Он рассчитывается по формуле [19]

$$
\text { ЧДД }=И+\sum_{i=1}^{n} \frac{Д_{i}}{(1+r)^{\prime}} \text {, }
$$

где И - начальные инвестиции;

$n$ - число лет, в течение которых инвестиционный проект приносит доход (на практике используется определенный горизонт планирования, который короче полного срока эксплуатации проекта);

ДП ${ }_{i}$ - денежный поток в течение периода $i$;

$r$ - ставка дисконтирования.

Применительно к проекту внедрения «Индустрии 4.0» ДП ${ }_{i}$ может быть рассчитан по формуле:

$$
\text { ДП }{ }_{i}=\left(C_{2 i}-C_{1 i}\right)+Д B_{i}
$$

где $C_{2 i}$ - издержки на функционирование системы вещевого обеспечения в $i$-м году в случае внедрения технологий «Индустрии 4.0»;

$C_{1 i}$ - издержки на функционирование системы вещевого обеспечения в $i$-м году в случае отказа от внедрения технологий «Индустрии 4.0»;

ДВ ${ }_{i}$ - дополнительные выгоды, получаемые благодаря использованию технологий «Индустрии 4.0» в $i$-м году (их источником может быть, например, продажа или сдача в аренду ставших избыточными складских мощностей, сокращение персонала, оптимизация логистических цепей поставок вещевого имущества и т. д. [12]).

Величина ЧДД измеряется в денежных единицах и несопоставима с величиной военного эффекта. Это означает, что необходимо обеспечить соизмеримость величины ЧДД и военного эффекта, т. е. перейти к безразмерному показателю экономического эффекта $E$. 
Пусть рассматривается $m$ вариантов внедрения технологий «Индустрии 4.0» в сфере вещевого обеспечения войск (сил). Тогда для каждого из вариантов рассчитывается значение ЧДДј $(j \in(1,2, \ldots, m))$ по формуле (1). Значение безразмерного показателя экономического эффекта $E_{j}$ для каждого варианта будет рассчитываться по формуле:

$$
E_{j}=\frac{\text { ЧДД }_{j}-\text { ЧДД }}{\text { ЧДД }_{\max }-\text { ЧДД }} \times 99+1
$$

где ЧДД ${ }_{\min }$ - наименьшее значение чистого дисконтированного дохода из всех вариантов $m$;

ЧДД ${ }_{\max }$ - наибольшее значение чистого дисконтированного дохода из всех вариантов $m$.

Формула (3) построена на основе стобалльной (от 1 до 100 баллов) шкалы безразмерного экономического эффекта (т. е. при ее использовании наименьшему значению чистого дисконтированно-

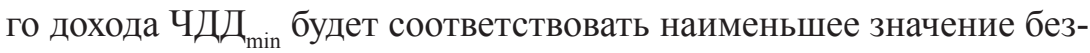
размерного экономического эффекта $E_{\text {min }}$, равное 1 , а наибольшему значению чистого дисконтированного дохода ЧДД ${ }_{\max }-$ наибольшее значение безразмерного экономического эффекта $E_{\max }$, равное 100 ).

Военный эффект ВЭ является безразмерным показателем и может быть рассчитан по формуле:

$$
\mathrm{B} Э=\mathrm{Y}_{2}-\mathrm{Y}_{1},
$$

где $\mathrm{V}_{2}$ - прогнозный уровень удовлетворенности военнослужащих после внедрения технологий «Индустрии 4.0»;

$\mathrm{y}_{1}$ - уровень удовлетворенности военнослужащих при текущей модели организации вещевого обеспечения.

Прогнозное значение военного эффекта оценивается путем опроса военнослужащих. Поскольку разные военнослужащие поразному будут оценивать свои ожидания от внедрения «Индустрии 4.0» в сфере вещевого обеспечения, а также свой текущий уровень удовлетворенности, то для формулы (4) следует брать средние по выборке значения $\mathrm{Y}_{1}$ и $\mathrm{Y}_{2}$.

Пусть рассматривается $m$ вариантов внедрения технологий «Индустрии 4.0». Можно предположить, что каждый вариант будет ох- 
ватывать разное количество военнослужащих (например, при их внедрении по родам войск, по группам военнослужащий - рядовой, младший офицерский, старший офицерский и т. д. состав), и поэтому для каждого j-го варианта целесообразно оценить совокупный военный эффект ВЭ${ }_{\text {int, }, \text { : }}$

$$
\mathrm{B}_{\mathrm{int}, j}=\mathrm{K}_{j} \times \mathrm{B}_{j}
$$

где $K_{j}-$ количество военнослужащих, охваченных $j$-м вариантом внедрения «Индустрии 4.0».

При помощи формулы (5) можно оценить совокупный прирост удовлетворенности по определенной группе военнослужащих. Показатель совокупного военного эффекта ВЭ ективным по сравнению с показателем военного эффекта ВЭ, поскольку он учитывает количество военнослужащих, охваченных качественным улучшением функционирования системы вещевого обеспечения. Отметим, что, в отличие от безразмерного показателя военного эффекта ВЭ, совокупный военный эффект ВЭ размерной величиной (он измеряется в количестве человек).

Безразмерная величина военного эффекта для $j$-го варианта внедрения «Индустрии 4.0» $M_{j}$ будет рассчитываться по формуле:

$$
M_{j}=\frac{\mathrm{B} Э_{\mathrm{int}, j}-\mathrm{B} Э_{\mathrm{int, \text {min }}}}{\mathrm{B} Э_{\mathrm{int, \text {max }}}-\mathrm{B} Э_{\mathrm{int, \text {min }}}} \times 99+1,
$$

где В $Э_{\text {int,min }}$ - наименьшее значение совокупного военного эффекта ВЭ ${ }_{\text {int }}$ из $m$ вариантов;

ВЭ ${ }_{\text {int,max }}$ - наибольшее значение совокупного военного эффекта ВЭ ${ }_{\text {int }}$ из $m$ вариантов.

Как и формула (4), формула (6) построена на основе стобалльной (от 1 до 100) шкалы значений безразмерного военного эффекта $M$.

На сегодняшний день известно большое количество алгоритмов свертки частных показателей для оценки величины интегрального эффекта [9]. Мы полагаем, что наиболее удобным будем использование алгоритма свертки на основе расчета среднего взвешенного арифметического. С учетом этого значение военно-экономического эффекта для $j$-го варианта внедрения технологий «Индустрии 
4.0» в сфере вещевого обеспечения $M E_{j}$ может быть рассчитано по формуле

$$
M E_{j}=a E_{j}+b M_{j},
$$

где $a$ и $b$-веса экономического и военного эффектов соответственно (определяются экспертно).

Для внедрения следует рекомендовать тот вариант применения «Индустрии 4.0» в сфере вещевого обеспечения военных потребителей, для которого $M E_{j}=\max [1]$.

\section{Обсуждение}

Предложенные нами методики расчета частных показателей экономического эффекта (формулы $(1,2))$ и военного эффекта (формулы $(4,5))$, а также интегрального показателя военно-экономического эффекта (формулы $3,6,7)$ ), позволяют, при наличии достаточного объема исходных данных, определить прогнозные и фактические значения ключевых показателей, необходимых для принятия решения о целесообразности внедрения технологий «Индустрии 4.0» в сфере вещевого обеспечения военных потребителей.

Отличительным признаком нашей методики является то, что она позволяет рассчитать военно-экономический эффект только при наличии более одного варианта внедрения технологий «Индустрии 4.0» (потому что только в этом случае возможно обеспечить сопоставимость используемых показателей). Эта характеристика методики может рассматриваться в качестве ее недостатка, однако с практической точки зрения эта проблема не имеет решающего значения: в реальных условиях, как правило, одновременно рассматривается несколько возможных вариантов поведения. Кроме того, простейшим способом создания альтернатив является сравнение существующего состояния системы вещевого обеспечения, и того состояния, которое ожидается после внедрения технологий «Индустрии 4.0». В этом случае предложенная нами методика позволит определить, является ли предпочтительным внедрение технологий «Индустрии 4.0» по сравнению с продолжением использования существующей модели организации системы вещевого обеспечения. 
Таким образом, на практике всегда существует не менее двух вариантов поведения, что гарантирует наличие условий для применения предложенной нами методики.

\section{Выводы}

Мы можем сформулировать следующие выводы:

- экономический эффект от внедрения технологий «Индустрии 4.0» носит долгосрочный характер, а само это внедрение в краткосрочной перспективе может потребовать достаточно больших затрат для организации технологического перевооружения как самой службы вещевого обеспечения ВС РФ, так и ее гражданских поставщиков;

- военный эффект будет носить преимущественно качественный характер и скажется в первую очередь на уровне удовлетворенности военнослужащих условиями несения службы (степенью удовлетворения потребностей в обеспечении вещевым имуществом и его качеством);

- при оценке военного эффекта необходимо принимать во внимание, какое количество военнослужащих будет охвачено технологиями «Индустрии 4.0».

\section{Список литературы}

1. Богатырева С.В., Титов А.Б., Куприянова М.Ю. Экономическая эффективность как основа формирования управленческих решений // Экономика и менеджмент систем управления. 2016. Т. 20. № 2.1. C. $116-122$.

2. Бычков А.В., Стулов С.В., Курбанов А.Х. Оценка военно-экономической эффективности применения логистического потенциала Коллективных сил оперативного реагирования // Ученые записки Крымского инженерно-педагогического университета. 2017. № 4. С. 28-33.

3. Давыдкин Е.В. Нечеткая модель оценка эффективности аутсорсинга // Экономический анализ: теория и практика. 2012. № 5. С. 52-55.

4. Жизневский А.Н., Курбанов А.Х., Титов В.А. Методика военно-экономического обоснования внедрения системы автоматизированного 
учета вещевого имущества м моенной организации на основе применения контрольных идентификационных знаков // Экономика и предпринимательство. 2018. № 6. С. 889-895.

5. Исавнин А.Г., Фархутдинов И.И. Оценка экономического эффекта от применения модели сорсингового маневра на промышленном предприятии // Региональная экономика: теория и практика. 2014. № 43. C. 45-50.

6. Исавнин А.Г., Фархутдинов И.И. Оценка экономической эффективности аутсорсинга с помощью системы «директ-костинг» // Автомобильная промышленность. 2013. № 6. С. 1-4.

7. Кирьянов И.В. Количественная оценка трансакционных издержек организации. Общий методический подход // Вестник НГУЭУ. 2015. № 1. С. $78-101$.

8. Котляров И.Д. Организация эффективного военно-гражданского сотрудничества // Ресурсное обеспечение силовых министерств и ведомств: вчера, сегодня, завтра. Сборник статей II Международной научно-практической конференции. Пермь: Пермский военный институт войск Национальной гвардии Российской Федерации, 2016. С. 177-181.

9. Котляров И.Д. Алгоритм отбора аутсорсеров по критерию способности обеспечить целевые значения показателей, описывающих передаваемый процесс // Проблемы экономики и управления нефтегазовым комплексом. 2012. № 10. С. 50-54.

10. Котляров И.Д. Проблемы оценки экономического эффекта аутсорсинга // Проблемы экономики и управления нефтегазовым комплексом. 2013. № 6. С. 9-13.

11. Котляров И.Д. Принятие решение об использовании аутсорсинга с учетом фактора риска // Вісник Хмельницького національного університету. Економічні науки. 2015. Т. 3. № 3. С. 106-110.

12. Котляров И.Д. Проблемы оценки эффективности аутсорсинга // Вестник Института экономики Российской академии наук. 2017. № 6. С. 87-99.

13. Красовитов Р.А., Курбанов А.Х. Научно-методическое сопровождение внедрения концепции «Индустрии 4.0» в сфере вещевого обеспечения военных потребителей // Экономика и предпринимательство. 2017. № 10-2 (87-2). С. 761-767. 
14. Курбанов А.Х. Экономико-математическая модель оценки организационно-экономической эффективности внедрения аутсорсинга // Проблемы экономики и управления нефтегазовым комплексом. 2012. № 2. С. 40-44.

15. Курбанов А.Х., Клюкин Е.В. Обоснование целесообразности и оценка военно-экономического эффекта от применения бенчмаркинга в управлении вещевым обеспечением военной организации // Coвременная наука: актуальные проблемы теории и практики. Серия: Экономика и право. 2015. № 11-12. С. 46-50.

16. Курбанов А.Х., Колобов Е.О. Обоснование инструментов и подходов оценки военно-экономической эффективности применения контрейлерных перевозок в интересах материального обеспечения войск (сил) // Экономика и предпринимательство. 2016. № 9. С. 74-78.

17.Курбанов А.Х., Крон Л.А. Сопротивление персонала организации внедрению управленческих инноваций: причины, проблемы и пути решения // Проблемы экономики и управления нефтегазовым комплексом. 2013. № 8. С. 22-25.

18. Курбанов А.Х., Лабазанов С.Г., Плотников В.А. Организационноэкономические инновации в деятельности силовых структур государства // Научно-технические ведомости Санкт-Петербургского государственного политехнического университета. Экономические науки. 2006. № 48-2. С. 137-142.

19. Плотников В.А. Интеграция военного и гражданского секторов экономики как тенденции строительства военной организации страны (по материалам Тыла Вооруженных Сил Российской Федерации) // Вооружение и экономика. 2010. № 2. С. 85-88.

20. Рогова Е.М. Ткаченко Е.А. Финансовый менеджмент. М.: Юрайт, 2011. $540 \mathrm{c}$.

21. Толкачев С.А. Индустрия 4.0 и ее влияние на технологические основы экономической безопасности России // Вестник РАЕН. 2017. T. 17. № 1. C. 79-83.

22. Чулков Д.Н. Оценка экономической эффективности применения шаблонов бизнес-процессов // Экономика и предпринимательство. 2015. № 9-2. С. 1014-1017. 
23. Щетинина Н.Ю. Индустрия 4.0: практические аспекты реализации в российских условиях // Модели, системы, сети в экономике, технике, природе и обществе. 2017. № 1. С. 75-84.

24. Юдина М.А. Индустрия 4.0: перспективы и вызовы для общества // Государственное управление. Электронный вестник. 2017. № 60. C. $197-215$.

25. Юмаев Е.А. Инновационно-промышленная политика в свете перехода к Индустрии 4.0: зарубежные тенденции и вызовы для России // Журнал экономической теории. 2017. № 2. С. 181-185.

26. Ямалетдинов А.Ф. Аутсорсинг в военной организации: факторы успеха и оценка военно-экономической эффективности // Экономика и предпринимательство. 2014. № 12-2. С. 729-733.

\section{References}

1. Bogatyreva S.V., Titov A.B., Kupriyanova M.Yu. Ekonomicheskaya effektivnost kak osnova prinyatiya resheniy [Economic effectiveness as a basis of decision making]. Ekonomika $i$ menedzhment system upravleniya [Economy and management of regulation systems], 2016, V. 20, no 2.1, pp. 116-122.

2. Bychkov A.V., Stulov S.V., Kurbanov A.Kh. Osenka voenno-ekonomicheskoy effektivnosti primeneniya logisticheskogo potentsiala Kollektivnykh sil operativnogo reagirovaniya [Evaluation of the military and economic effectiveness of the use of logistic potential of Collective forces of operative reaction]. Uchenye zapiski Krymskogo inzhenerno-pedagogicheskogo universiteta [Scientific notes of the Crimean university of engineering and pedagogy], 2017, no 4, pp. 28-33.

3. Davydkin E.V. Nechetkaya model otsenki effektivnosti autsorsinga [A fuzzy model of evaluation of outsourcing effectiveness]. Ekonomicheskiy analiz: teoriya i praktika [Economic analysis: theory and practice], 2012, no 5, pp. 52-55.

4. Zhizevsky A.N., Kurbanov A.Kh., Titov V.A. Metodika voenno-ekonomicheskogo obosnovaniya vnedreniya sistemy avtomatizirovannogo ucheta veshchevogo imushchestva v voennoy organizatsii na osnove primeneniya kontrol'nykh identifikatsionnykh znakov [A method of 
military and economic substantiation of implementation of an automated system of accounting for material goods in the military organization based on control identification signs]. Ekonomika i predprinimatelstvo [Economics and entrepreneurship], 2018, no 6, pp. 889-895.

5. Isavnin A.G., Farkhutdinov I.I. Otsenka ekonomicheskogo effekta ot primeneniya modeli sorsingovogo manevra na promyshlennom predpriyatii [Evaluation of the economic effect of the sourcing maneuver in industrial company]. Regionalnaya ekonomika: teoriya i praktika [Regional economy: theory and practice], 2014, no 43, pp. 45-50.

6. Isavnin A.G., Farkhutdinov I.I. Otsenka ekonomicheskoy effektivnosti autsorsinga s pomoshchu sistemy "direct kosting" [Evaluation of the economic effectiveness of outsourcing on the basis of the system "direct costing"]. Avtomobilnaya promyshlennost [Automobile industry], 2013, no 6, pp. 1-4.

7. Kir'yanov I.V. Kolichestvennaya otsenka transaktsionnykh izderzhek organizatsii. Obshchiy metodicheskiy podkhod [Quantitative evaluation of transaction costs of an organization. A general methodological approach]. Vestnik NGUEU [NGUEU journal], 2015, no 1, pp. 78-101.

8. Kotliarov I.D. Organizatsiya effektivnogo voenno-grazhdanskogo sotrudnichestva [Organization of an effective military and civil cooperation]. Resursnoe obespechenie silovykh ministerstv $i$ vedomstv: vchera, segodnya, zavtra [Resource provision for enforcement ministries and organizations: yesterday, today, tomorrow]. Collected works of the II International scientific and practical conference. Perm: Perm military institute of the armed forces of the National Guard of Russian Federation, 2016, pp. 177-181.

9. Kotliarov I.D. Algoritm otbora autsorserov po kriteriyu sposobnosti obespechit tselevye znacheniya pokazateley, opisyvayushchikh peredavaemyy protsess [An algorithm of selection of outsources based on the criterion of their ability to ensure target values of indicators that describe the outsourced process]. Problemy ekonomiki i upravleniya neftegazovym kompleksom [Problems of economics and management in the oil and gas complex], 2012, no 10, pp. 50-54.

10. Kotliarov I.D. Problemy otsenki ekonomicheskogo effekta autsorsinga [Problems of evaluation of economic effect of outsourcing]. Problemy 
ekonomiki i upravleniya neftegazovym kompleksom [Problems of economics and management in the oil and gas complex], 2013, no 6, pp. 9-13.

11. Kotliarov I.D. Prinyatie resheniya ob ispol'zovanii autsorsinga s uchetom faktora riska [Decision-making for the use of outsourcing taking into account the factor of risk]. Visnyk Khmel'nitskogo natsional'nogo universytetu. Ekonomichni nauky [Journal of Hmelnitsky national university. Economic sciences], 2015, V. 3, no 3, pp. 106-110.

12. Kotliarov I.D. Problemy otsenki effektivnosti autsorsinga [Problems of evaluation of effectiveness of outsourcing]. Vestnik Instituta ekonomiki Rossiyskoy akedemii nauk [Journal of the Institute of Economics of Russian Academy of Sciences], 2017, no 6, pp. 87-99.

13. Krasovitov R.A., Kurbanov A.Kh. Nauchno-metodicheskoe soproozhdenie vnedreniya kontseptsii "Industrii 4.0" v sfere veshchevogo odespecheniya voennykh potrebiteley [Scientific and methodological support of the implementation of the concept of the "Industry 4.0" in the field of material supply to military customers]. Economika i predprinimatel'stvo [Economics and entrepreneurship], 2017, no 10-2, pp. 761-767.

14. Kurbanov A.Kh. Ekonomiko-matematicheskaya model otsenki organizatsionno-ekonomicheskoy effektivnosti vnedreniya autsorsinga [Economic and mathematical model of organizational and economic effectiveness of implementation of outsourcing]. Problemy ekonomiki i upravleniya neftegazovym kompleksom [Problems of economics and management in the oil and gas complex], 2012, no 2, pp. 40-44.

15. Kurbanov A.Kh., Klyukin E.V. Obosnovanie tselesoobraznosti i otsenka voenno-ekonomicheskogo effekta ot primeneniya benchmarkinga $\mathrm{v}$ upravlenii veshchevym obespecheniem voennoy organizatsii [Substantiation of the necessity and evaluation of economic and military effect of use of benchmarking in the management of material supply for a military organization]. Sovremennaya nauka: aktualnye problemy teorii i praktiki. Seriya: Ekonomika i pravo [Modern science: actual problems of theory and practice. Series: Economics and law], 2015, no 11-12, pp. 46-50.

16. Kurbanov A.Kh., Kolobov E.O. Obosnovanie instrumentov i podkhodov otsenki voenno-ekonomicheskoy effektivnosti primeneniya kontreylernykh perevozok v interesakh material'nogo obespecheniya voysk 
(sil) [Substantiation of tools and approaches of evaluation of military and economic effectiveness of use of contrailer transport for the material supply to the army]. Ekonomika i predprinimatelstvo [Economics and entrepreneurship], 2016, no 9, pp. 74-78.

17. Kurbanov A.Kh., Kron L.A. Soprotivlenie personala organizatsii vnedreniyu upravlencheskikh innovatsiy: prichiny, problemy i puti resheniya [Resistance of the personnel of an organization to implementation of management innovations: reasons, problems and ways of solving]. Problemy ekonomiki i upravleniya neftegazovym kompleksom [Problems of economics and management in the oil and gas complex], 2013, no 8, pp. 22-25.

18. Kurbanov A.Kh., Labazanov S.G., Plotnikov V.A. Organizatsionno-ekonomicheskie innovatsii v deyatelnosti silovykh struktur gosudarstva [Organizational and economic innovations in the activity of the enforcement structures of the state]. Nauchno-tekhnicheskie vedomosti Sankt-Peterburgskogo gosudarstvennogo politekhnicheskogo universiteta. Ekonomicheskie nauki [Scientific and technical journal of St. Petersburg state polytechnic university. Economic sciences], 2006, no 48-2, pp. 137-142.

19. Plotnikov V.A. Integratsiya voennogo i grazhdanskogo sektorov ekonomiki kak tendentsiya stroitelstva voennoy organizatsii strany (po materialam Tyla Vooruzhennykh Sil Rossiyskoy Federatsii) [Integration of the military and civil sectors of the economy as a trend of building of military organization of the country (based on examples of the Logistics Service of the Armed Forces of Russian Federation]. Vooruzhenie $i$ ekonomika [Weapons and economics], 2010, no 2, pp. 85-88.

20. Rogova E.M., Tkachenko E.A. Finansovyy menedzhment [Financial management]. Moscow: URAYT, 2011. 540 p.

21. Tolkachev S.A. Industriya 4.0 i ee vliyanie na tekhnologicheskie osnovy ekonomicheskoy bezopasnosti Rossii [Industry 4.0 and its impact on the technological basis of the economic security of Russia]. Vestnik RAEN [RAEN journal], 2017, V. 17, no 1, pp. 79-83.

22. Chulkov D.N. Otsenka ekonomicheskoy effektivnosti primeneniya shablonov biznes-protsessov [Evaluation of economic effectiveness of use of standards of business processes], Ekonomika i predprinimatelstvo [Economics and entrepreneurship], 2015, no 9-2, pp. 1014-1017. 
23. Shchetinina N. Yu. Industriya 4.0: prakticheskie aspekty realizatsii v rossiyskikh usloviyakh [Industry 4.0: practical aspects of implementation in Russian situation]. Modeli, sistemy, seti v ekonomike, tekhnike, prirode i obshchestve [Models, systems, networks in economy, technics, nature and society], 2017, no 1, pp. 75-84.

24. Yudina M. A. Industriya 4.0: perspektivy i vyzovy dlya obshchestva [Industry 4.0: prospects and challenges for the society]. Gosudarstvennoe upravlenie. Elektronnyy vestnik [State administration. Electronic journal], 2017, no 60, pp. 197-215.

25. Yumaev Ye. A. Innovatsionno-promyshlennaya politika v svete perekhoda $\mathrm{k}$ Industrii 4.0: zarubezhnye tendentsii i vyzovy dlya Rossii [Innovative industrial policy from the point of view of the Industry 4.0: foreign trends and challenges for Russia]. Zhurnal ekonomicheskoy teorii [Journal of economic theory], 2017, no 2, pp. 181-185.

26. Yamaletdinov A. F. Autsorsing v voennoy organizatsii: factory uspekha i otsenka voenno-ekonomicheskoy effektivnosti [Outsourcing in the military organization: factors of success and evaluation of military and economic effectiveness]. Ekonomika i predprinimatelstvo [Economics and entrepreneurship], 2014, no 12-2, pp. 729-733.

\section{ДАННЫЕ ОБ АВТОРЕ}

Красовитов Роман Александрович, старший преподаватель кафедры Технологии и товароведения одежды и обуви Вольский военный институт материального обеспечения ул. М. Горького, 3, г. Вольск, Саратовская обл., 412901, Российская Федерация roma.krasovitov@yandex.ru

\section{DATA ABOUT THE AUTHOR}

Krasovitov Roman Aleksandrovich, Senior lecturer, Chair of Technologies of Cloths and Shoes Volsk Military Institute of Logistics 3, M. Gorky Str., Volsk, Saratov region, 412901, Russian Federation roma.krasovitov@yandex.ru 